\author{
D. GRAMBLIČKOVÁ, E. BEDNÁROVÁ, \\ M. MINÁRIK
}

\section{LESSONS LEARNED AND EXPERIENCE GAINED FROM THE APPLICATION OF THE FEM TO SOLVE TRANSIENT FLOW FILTRATION TASKS}

\section{ABSTRACT}

The frequent occurrence of floods in recent times has motivated discussions of experts who concentrate on reviewing the safety of flood dikes. Due to their line character and the often unknown composition of their bodies and subsoil, this task is very complicated. The proposed paper deals with some risks involving the safety of flood dikes and possibilities for their treatment in Slovakia. Attention is also paid to the lessons learned and experience gained from the application of the finite element method by solving the above-mentioned problems.

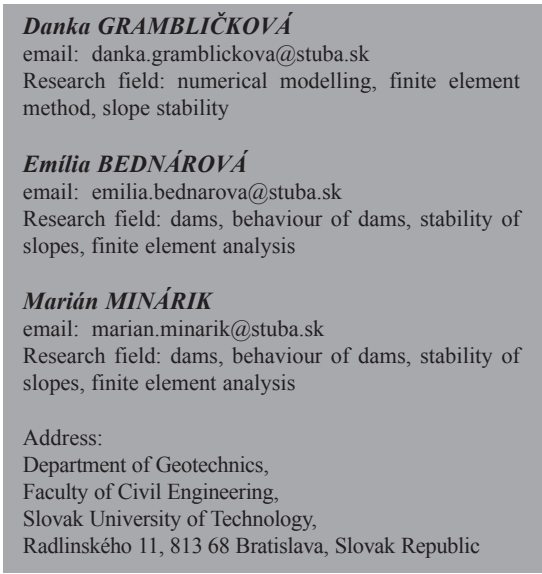

\section{KEY WORDS}

- Flood,

- dikes,

- subsoil

- uplift,

- filtration velocity,

- safety,

- finite element method

\section{INTRODUCTION}

The negative impact of floods on the environment coupled with broad economic losses is indisputable (fig. 1). Flood losses and total costs for remedial work during the years 1996 - 2007 in Slovakia reached 20429.08 million SK and ranged from 53.79 million SK in 2003 to 4584.30 million SK in 1999. A considerable amount of financial damages was also caused by the failing of flood dikes (FD). With the goal of preventing such losses caused by the failure of flood protective measures, it is necessary to re-evaluate the stability of dikes and eventually design appropriate protective measures. Consequently, an analysis of the risk factors endangering the safety of FD is necessary.

\section{ANALYSIS OF CONCOMITANT CIRCUMSTANCES SIGNALLING THREATS TO THE SAFETY OF A FLOOD DIKE}

Threads to the safety of a FD are often signalled by concomitant circumstances involving extreme hydrodynamic loading of dikes during floods. For example, during flood discharges on the Danube in August 2002 (fig. 2), numerous outflows and wet areas occurred in adjacent regions of a dike below Bratislava, which signalled the breaking of an overburden with the movement of fine sand particles in soil.

Floods on the Moravia river in 1977 (fig. 3) were followed by large seepages at the downstream toe of a dike, which caused flooding of the villages of Záhorská Ves - Suchohrad and signalled a thread 


\section{SIOYALY JOUSSILL \\ 0.

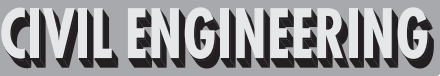

2010/3 PAGES $7-13$

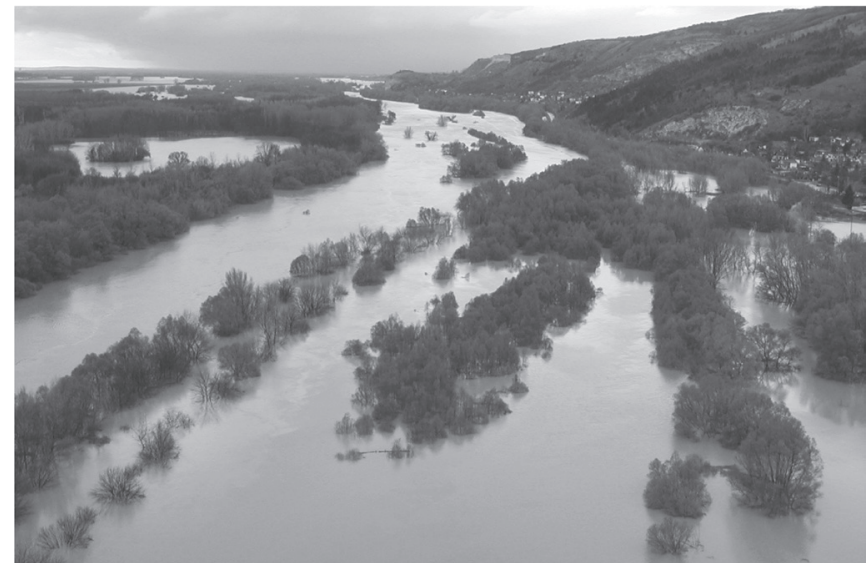

View from castle Devin

a) View on flooded Moravia river near castle Devín - 2002 (photo: F. Valašik)

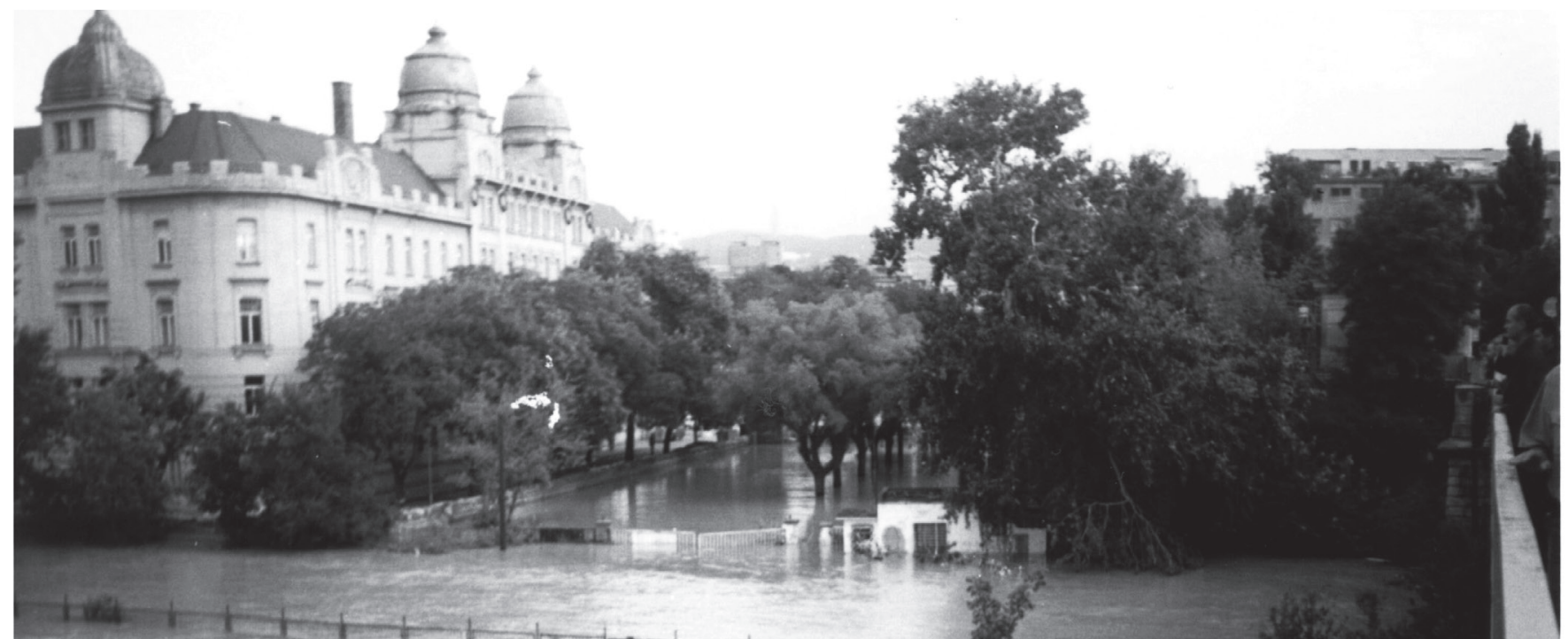

b) Bratislava - flood in year 2002 (photo: M. Jarolinová) view from Old bridge (Gondova street and Šafárikovo square)

Fig. 1 Negative impact of floods on environment

to the FD's stability. In the surroundings outflows also occurred with the movement of fine particles in the soil that confirmed the likelihood of failures of the filtration's stability, so the critical uplifts and velocities were probably exceeded.

During floods on the Torysa river occurred in recent years near the village of Sady nad Torysou on the downstream toe of the FD outflows, which signalled possible failure of the FD's stability (fig. 4). The body and surroundings of the FD were also endangered by overflowing (housing constructions are situated in the vicinity of the downstream toe), which was secured during the flood by rising

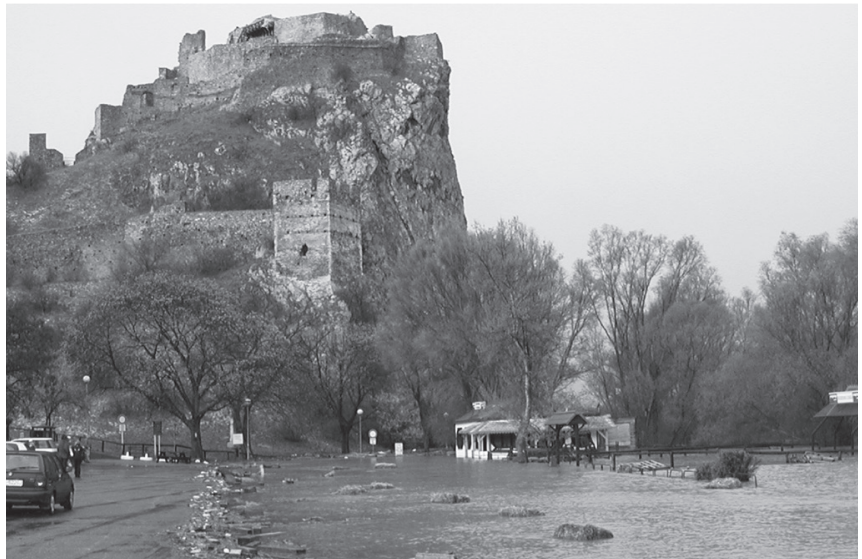

under castle Devín 


\section{IDYALS JOUSSIAL 0)

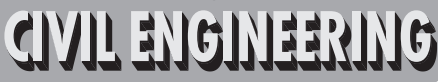

2010/3 PAGES $7-13$

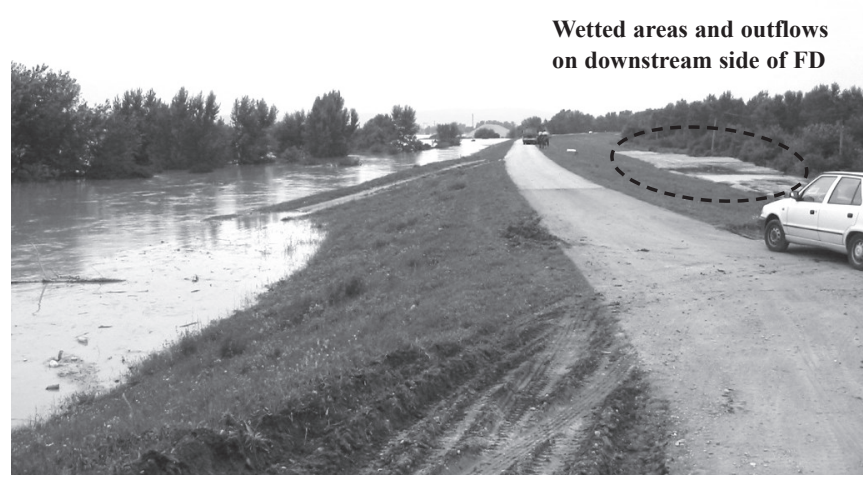

Fig. 2 Seepages through Danube river flood dike under Bratislava - august 2002 (photo: A. Kasana)

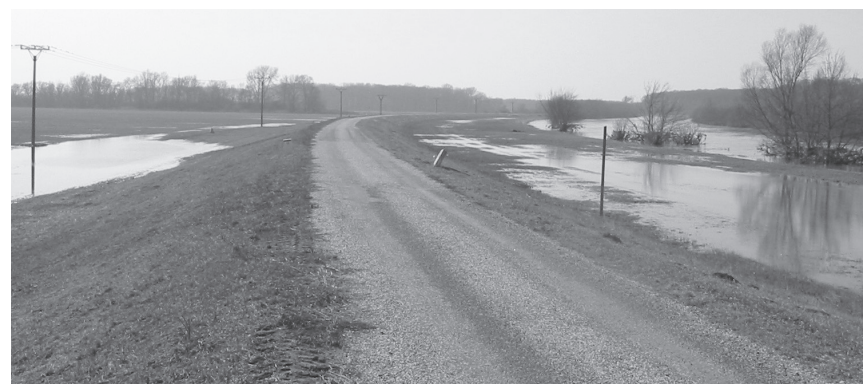

Fig. 3 Seepages through Moravia river flood dike - 1997 (photo: P. Virág)

risk factors and possibilities for their treatment. The selection of the optimal treatment is affected by several factors - morphology, the geological composition of a flood dike's body and subsoil, owner relationships, etc. It is necessary to fairly investigate the effect of the optimal treatment on any changes in the filtration regime, mainly from the viewpoint of eliminating the risk factors. In most cases, it is difficult to extrapolate the experience gained from solving problems at one locality to an other locality.

The Finite Element Method (FEM) belongs among the methods which are commonly used for reviewing the safety of flood dikes and also for the design of an optimal treatment. In cases of the occurrence of flood discharges, the tasks involve the nature of the transient flow. The difficulty of the tasks is indisputable, and is complicated by the randomness of the flood's scale and occurrence, and also uncertainty concerning the material properties that characterise the environment of the seepage. Creating a representative model and simulating the in-situ conditions belongs among the most important and most complicated parts of solving the task. The following sections discuss some lessons learned and experience gained with the input

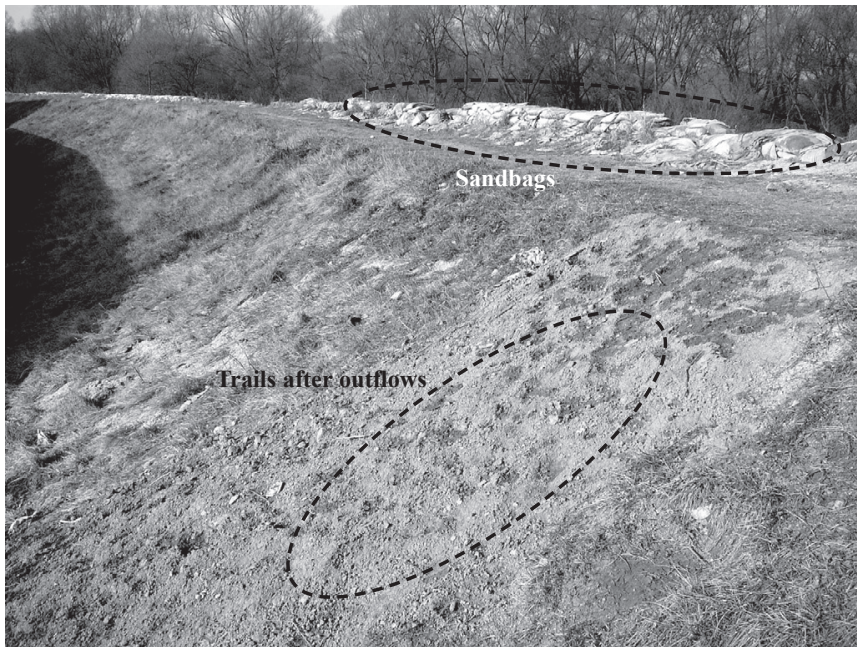

Fig. 4 Torysa river FD, 2006 - trails after outflows on downstream side and residues of sandbags securing FD from overflowing (photo: E. Bednárová)

parameters of the environment, which were obtained by applying FEM in order to solve various practical tasks.

\section{SOLUTION TECHNIQUES}

The mathematical solution for the transient flow of underground and seeping water is based on the application of the Continuity relation and Darcy's law. Computing three-dimensional numerical models is very difficult, from the point of view of creating the model itself; it is also very time consuming, because of the need to solve multiple alternative tasks. Therefore, 3D models are often substituted by solution in a vertical or horizontal plane. For a plane model, the following formula is applied [1]:

$\frac{\partial}{\partial x}\left(k_{x} b \frac{\partial h}{\partial x}\right)+\frac{\partial}{\partial y}\left(k_{y} b \frac{\partial h}{\partial y}\right)=\left(S_{v}+b S_{s}\right) \cdot \frac{\partial h}{\partial t}-q$

Where $h$ is the pressure head $(m), b$ is the saturated thickness $(m)$, $k_{x}, k_{y}$ are the filtration coefficients in the direction of the $x$ and $y$ axes respectively $\left(m . s^{-1}\right), t$ is the time $(s), S_{v}$ is the specific yield for any unconfined aquifers, $S_{S}$ is the specific storage $\left(\mathrm{m}^{-1}\right)$, and $q$ is a sink or source term $\left(m \cdot s^{-1}\right)$. Note that the sign convention for $q$ is positive for a recharge and negative for a discharge.

The credibility of FEM analysis is equal to the reality of the numerical model. Creating a representative model simulating the in-situ conditions requires defining of the solution area, the material 
Table 1. The most frequent concomitant circumstances signalling threats to the safety of a flood dike

\begin{tabular}{|l|l|l|l|}
\hline \multicolumn{1}{|c|}{\begin{tabular}{c}
\multicolumn{1}{|c}{ Concomitant } \\
phenomenon
\end{tabular}} & \multicolumn{1}{|c|}{ Reasons } & \multicolumn{1}{c|}{ Treatment } \\
\hline $\begin{array}{l}\text { Wet areas in } \\
\text { surroundings }\end{array}$ & $\begin{array}{l}\text { Seepages through subsoil; } \\
\text { Geological composition of the } \\
\text { subsoil }\end{array}$ & $\begin{array}{l}\text { Flooding of the surroundings; } \\
\text { Surface erosion; Breaking of the } \\
\text { overburden }\end{array}$ & $\begin{array}{l}\text { Stabilizing fill; Protection of the } \\
\text { subsoil; Drainage system }\end{array}$ \\
\hline $\begin{array}{l}\text { Wetting of the } \\
\text { downstream toe }\end{array}$ & $\begin{array}{l}\text { Seepages through the body or } \\
\text { subsoil of the FD; Excess of critical } \\
\text { uplifts in the dike's toe }\end{array}$ & $\begin{array}{l}\text { Decrease of the slope's stability; } \\
\text { Flooding of the surroundings; } \\
\text { Surface erosion Contact erosion }\end{array}$ & $\begin{array}{l}\text { Sealing the dike's body and protection } \\
\text { of the subsoil; Stabilizing fill; Surface } \\
\text { treatment of the slope - hardening }\end{array}$ \\
\hline $\begin{array}{l}\text { Outflows } \\
\text { Outflows }+ \\
\text { movement of fine } \\
\text { particles in the } \\
\text { soil }\end{array}$ & $\begin{array}{l}\text { Excess of the critical uplifts in the } \\
\text { subsoil; Preferred seepage paths } \\
\text { the subsoil + excess of the critical } \\
\text { velocities in the subsoil }\end{array}$ & $\begin{array}{l}\text { Flooding of the surroundings; } \\
\text { Breaking of the overburden }\end{array}$ & $\begin{array}{l}\text { Stabilizing fill; Protection of the } \\
\text { subsoil; Drainage system reducing the } \\
\text { uplift }\end{array}$ \\
\hline $\begin{array}{l}\text { Movement of } \\
\text { fine particles in } \\
\text { soil }\end{array}$ & $\begin{array}{l}\text { Seepages +excess of the critical } \\
\text { velocities in the subsoil }\end{array}$ & $\begin{array}{l}\text { Surface or internal erosion; } \\
\text { Endangering the safety of the FD } \\
\text { Decrease in the subsoil's bearing } \\
\text { capacity }\end{array}$ & $\begin{array}{l}\text { Stabilizing fill; Protection of the } \\
\text { subsoil; Drainage system }\end{array}$ \\
\hline $\begin{array}{l}\text { Overflowing of } \\
\text { the flood dike's } \\
\text { crest }\end{array}$ & $\begin{array}{l}\text { Change in the hydrological } \\
\text { conditions; Underestimating the } \\
\text { height of the FD; Additional } \\
\text { settlement of the FD (internal } \\
\text { erosion) }\end{array}$ & $\begin{array}{l}\text { Stabilizing fill; Protection of the } \\
\text { subsoil; Drainage system; Drainage } \\
\text { system reducing the uplift }\end{array}$ \\
\hline
\end{tabular}

properties, the boundary and initial conditions, and the parameters of the extreme hydrodynamic loading. Among the most important factors, belongs knowledge of the material properties of the seepage environment, which are determining factors of the flow's nature.

\section{EFFECT OF THE MATERIAL PROPERTIES ON CHANGES IN THE FILTRATION FLOW}

Of all the material properties $\left(k_{x}, k_{y}, S_{v} S_{s}\right)$ the highest impact on the nature of the flow is the filtration coefficient. A relatively high degree of attention is paid to estimating this parameter, because it is the subject of an engineering-geological investigation. Even though its results are often ambiguous, they are dependent on the method of estimation. In addition, this problem is complicated by the heterogeneity of the environment. By flood dikes, which specific is line character either sufficient engineering-geological investigation is often unavailable.

An even higher degree of uncertainty is in the parameters of the transient flow, i.e. in the coefficient of the specific yield for unconfined aquifers $S_{v}$ and in specific storage $S_{s}$. These are not the subject of an engineering-geological investigation; therefore, the estimation of their values for numerical modelling is always problematic. Knowledge concerning the rate of any filtration flow changes can considerably help us.

The coefficient of the specific yield for unconfined aquifers $S_{v}$ is defined as the volume of water which is released from the unit surface of the soil by the unit decrease of the underground water level and vice versa [2]. For estimating its Mucha presents the following formulas, which depend on the environment's permeability: $S_{v}=0.117^{7} \sqrt{k}$ - Becinsky (1960): where $k$ is in m.day ${ }^{-1}$ and $S_{v}=0.4+0.05 \cdot \log \left(k_{p}\right)-$ Luckner, where $k$ is in $m \cdot s^{-1}$. In table 1 are expressed its values after both authors. In the last column average values gained by extensive in situ measurements in the Sunada and McWhorter surroundings in the year 1977 are listed [3]. The margins of occurrence are noted in brackets.

The values of the coefficient of the specific yield for unconfined aquifers are in a one digit place range. Its impact on changes in filtration flow was detailed and analysed in the contribution [4].

The analysis presented (executed with an assumption of extreme hydrodynamic loading equivalent to the parameters observed during recent years) figure on the minimal effect of the $S_{v}$ value 
Table 2 Values of the coefficient of the specific yield for unconfined aquifers $S v$

\begin{tabular}{|c|c|c|c|}
\hline \multirow{2}{*}{$\begin{array}{c}\text { Permeability } \\
\left(\mathbf{m . s}^{-1}\right)\end{array}$} & $\begin{array}{c}\text { Becinsky } \\
(\mathbf{1 9 6 0})\end{array}$ & Luckner & Thomas (1996) \\
\hline $1.10^{-3}$ & 0.221 & 0.25 & $0.305(0.17-0.44)$ \\
\hline $1.10^{-4}$ & 0.159 & 0.20 & $0.305(0.18-0.43)$ \\
\hline $1.10^{-5}$ & 0.115 & 0.15 & $0.235(0.01-0.46)$ \\
\hline $1.10^{-6}$ & 0.082 & 0.10 & $0.095(0.01-0.18)$ \\
\hline
\end{tabular}

Table 3 Values of specific storage $S_{s}$

\begin{tabular}{|c|c|c|}
\hline \multirow{2}{*}{ material } & \multicolumn{2}{|c|}{$S_{\mathbf{s}}\left(\mathbf{m}^{-1}\right)$} \\
\cline { 2 - 3 } & Mucha (1987) & Thomas $(\mathbf{1 9 9 6 )}$ \\
\hline Soft clay & & $2.0 .10^{-2}-2.6 .10^{-3}$ \\
\hline Stiff clay & & $2.6 .10^{-3}-1.3 .10^{-3}$ \\
\hline Solid clay & & $1.3 .10^{-3}-9.2 .10^{-4}$ \\
\hline Loose sand & $1.0 .10^{-4}-1.0 .10^{-5}$ & $1.0 .10^{-3}-4.9 .10^{-4}$ \\
\hline Dense sand & $2.0 .10^{-5}-6.0 .10^{-6}$ & $2.0 .10^{-4}-1.3 .10^{-4}$ \\
\hline Dense sandy gravel & $2.0 .10^{-5}-5.0 .10^{-6}$ & $1.0 .10^{-4}-4.9 .10^{-5}$ \\
\hline Fractured rock & $7.0 .10^{-5}-4.0 .10^{-6}$ & $6.9 .10^{-5}-3.3 .10^{-6}$ \\
\hline Solid rock & $<4.0 .10^{-6}$ & $<3.3 .10^{-6}$ \\
\hline
\end{tabular}

on the filtration flow mode in an environment with a degree of permeability higher than $10^{-3} \mathrm{~m} \cdot \mathrm{s}^{-1}$ over a short term (several days) of extreme hydrodynamic loading. Concerning long-term floods, this difference trailed away, which indicates that in regions with such permeability, this characteristic is unessential mainly when modelling long-lasting floods. In the actual duration of maximal discharges (tens of days) and in soils with a lower degree of permeability than $10^{-6} \mathrm{~m} \cdot \mathrm{s}^{-1}$ the impact of $S_{v}$ on changes in the filtration flow mode is irrelevant. The yield for unconfined aquifers $S_{v}$ appears to be the most sensitive characteristic in soils with a permeability of $10^{-4}-10^{-5} \mathrm{~m} \cdot \mathrm{s}^{-1}$. Its impact on changes in filtration parameters signal the highest degree of differences, which are maintained for weeks. In these conditions satisfactory input data are necessary for creating a representative numerical model.

Specific storage $\boldsymbol{S}_{\boldsymbol{s}}$ is defined for confined layers with a tensioned water level such as a volume of water which is released from the unit surface of a $1 \mathrm{~m}$ thick confined layer by a unit decrease in the hydrostatic pressure and vice versa [2]. Its values for various materials are presented in table 2. In the first column according to Mucha [2] are assessed the values, in the second the values are measured in-situ and were obtained in the surroundings of Domenico in 1972 [3].

In the case of sandy and gravel soils the authors present several digit place differences. Bearing in mind the wide range of specific storage $S_{s}$ values, their estimation for numerical modelling is always problematic (in addition, it is not subject of a engineering geological investigation).

In this case, generally valid knowledge on the effect of specific storage $S_{s}$ on filtration flow changes can substantially help us. The values from table 2 indicate a reciprocal proportion with the filtration coefficient. The subject of our study was therefore an analysis of the effect of specific storage on filtration flow changes, considering the soil's permeability. This approach is also practical, because both characteristics of a flow are input data for the numerical model.

A numerical analysis was performed on the representative model (fig. 5 - above). Its parameters are characteristic of flood dikes built under Slovak conditions (a homogenous embankment consisting of silt or clay, a foundation base approximately $50 \mathrm{~m}$ wide and an impermeable overburden). The basic input parameters characterising an extreme hydrodynamic loading were derived from recent observations - the elevation of flood water level $\Delta \mathrm{h}=7.0 \mathrm{~m}$ over the average groundwater level with a maximal duration of a flood of up to 30 days. Generally, the geological composition of subsoil is one of the determining aspects concerning threats to the safety of flood dikes. Its permeability was considered to be from $k_{p o d}=1.10^{-3} \mathrm{~m} \cdot \mathrm{s}^{-1}$ to $1.10^{-6} \mathrm{~m} \cdot \mathrm{s}^{-1}$ with quite broad dispersion values for the specific storage (tab. 2), which incorporated a range of values according to the authors. The observed parameter was the time development of the uplifts $\Delta \mathrm{h}$ (fig. 5) on the impermeable overburden by extreme hydrodynamic loading. This phenomenon is important to investigate, because a risk of the breaking of the overburden exists with the possibility of activating the piping. During a flood these concomitant circumstances often occur. Fig. 5 also documents the effect of specific storage $S_{s}$ on this phenomenon in the case of subsoil permeability $10^{-5} \mathrm{~m} \cdot \mathrm{s}^{-1}$. The presented analysis signifies the following important trends:

- with the decreasing value of the subsoil's permeability, the effect of the specific storage value on the filtration flow mode considerably increases,

- after a specified time, this effect, which is dependent on the environment's permeability, is reduced (converging to a steadystate) by long-term extreme loading.

In accordance with above-mentioned facts it can be stated that:

- in a environment with a permeability of $1.10^{-3} \mathrm{~m} \cdot \mathrm{s}^{-1}$, the low effect of the specific storage values on changes in flow are apparent. Minimal (negligible) differences are observed in the initial phase of the extreme loading. During a long-lasting flood of a few days 


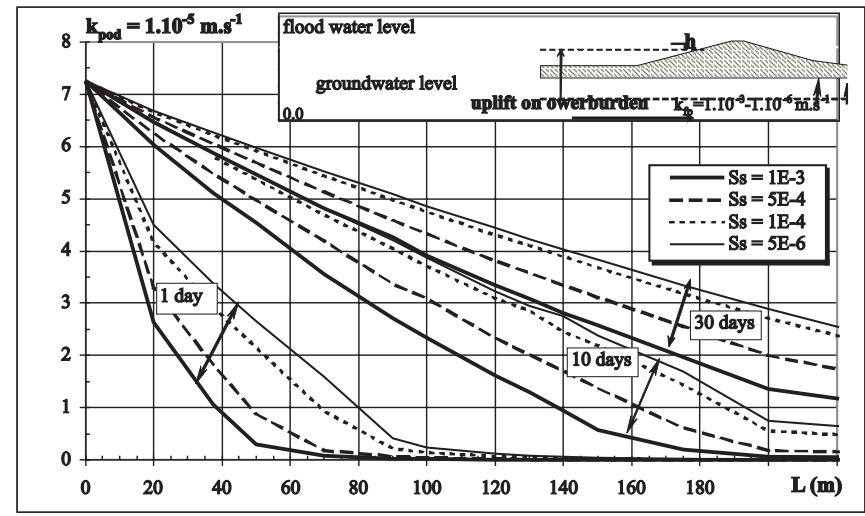

Fig. 5 Effect of specific storage on change of groundwater flow mode $-k_{\text {pod }}=1.10^{-5} \mathrm{~m} \cdot \mathrm{s}^{-1}$ and numerical model assumptions

or more this difference trailed away, which indicates, that in regions with such permeability, this characteristic is unessential,

- a subsoil permeability of $1.10^{-4} \mathrm{~m} \cdot \mathrm{s}^{-1}$ signals greater differences. This characteristic considerably affects the filtration flow mode by short-term extreme hydrodynamic loading. When modelling a flood with a duration of more than 5 days (in addition with respect to the length of the foundation base and surroundings) its effect is negligible,

- an environment with a degree of permeability lower than $1.10^{-5}$ $m . s^{-1}$ results in an unfavourable situation (fig. 4). A retarded flow increases differences in water levels affected by a different value of $S_{s}$ up to approximately $2 \mathrm{~m}$ and above. This difference lasts several tenths of days. Later the differences decrease to a solution converging on a steady-state,

- the permeability of a subsoil of $1.10^{-6} \mathrm{~m} \cdot \mathrm{s}^{-1}$ signals a seemingly different situation. It is caused only by the limited duration of an extreme load (considering the length of a flood of 30 days). With a long-lasting flood, the differences would increase. A positive fact is that during the duration of a flood in an environment with a permeability lower than $1.10^{-6} \mathrm{~m} \cdot \mathrm{s}^{-1}$, its effect on changes in the filtration flow mode is reduced in comparison with an environment with a permeability of $1.10^{-5} \mathrm{~m} \cdot \mathrm{s}^{-1}$.

\section{CONCLUSIONS}

The proposed analysis clarifies the importance of observed parameters in various geological environments. Although the research was conducted using a representative model with the above-mentioned geometric parameters, some of its results have a general character. The analysis validates the minimal effect of

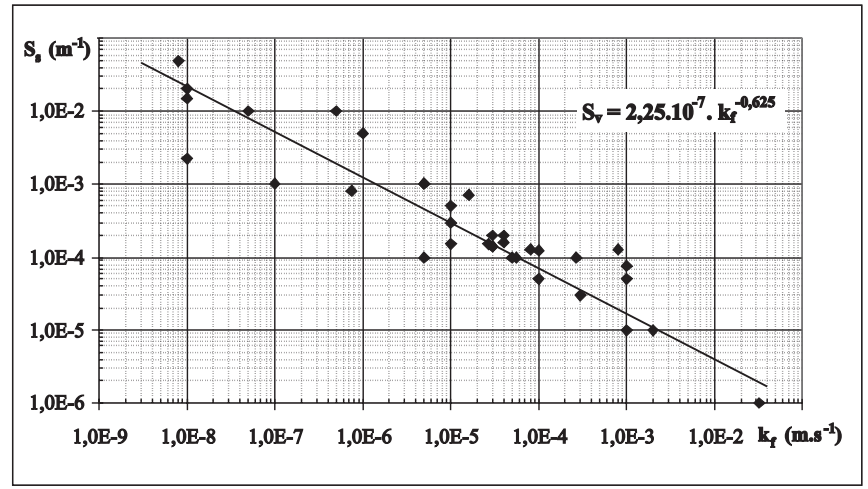

Fig. 6 Values of specific storage in dependence on material permeability

specific storage on a filtration flow mode in an environment more permeable than $10^{-3} \mathrm{~m} \cdot \mathrm{s}^{-1}$, during a long-lasting flood and also in an environment with a permeability of $10^{-4} \mathrm{~m} \cdot \mathrm{s}^{-1}$. On the other hand, in soils with a lower degree of permeability than $10^{-5} \mathrm{~m} . \mathrm{s}^{-1}$, the effect of this parameter is significant. In this case time plays an important role indeed.

During the length of actual flood discharges (weeks) it can be stated that the irrelevant impact of this parameter on the behaviour of the groundwater level is also in soils with a degree of permeability lower than $10^{-6} \mathrm{~m} \cdot \mathrm{s}^{-1}$. From this viewpoint specific storage is important mainly in soils with a degree of permeability of around $10^{-5} \mathrm{~m} . \mathrm{s}^{-1}$. In such conditions sufficient data are necessary for creating a sufficient numerical model.

The approximate value of specific storage can be estimated using fig. 6, where its values are expressed depending on the material's permeability. These results were retrieved and proved by solving broad practical problems in Slovakia using inverse models (back analyses) regarding water levels measured in situ under various load states. By common load states the measurement of water levels is usually part of monitoring dike safety. Under extreme load states these measurements are mostly missing. Therefore, it is also important to observe concomitant circumstances (mainly during floods) in surroundings such as waterlogged areas, the occurrence of outflows, piping, etc. Their monitoring should be part of technical and security surveillance and consistently recorded with remarks about their developments over time.

The paper discusses some risks threatening the safety of the flood dikes and possibilities for their treatment in Slovakia. Attention is paid to some lessons learned and experience gained with parameters input for numerical modelling of transient filtration flow using 


\section{IDOJLS JOUSSILL \\ 0."

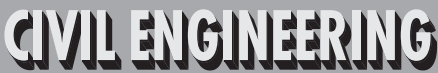

2010/3 PAGES $7-13$

FEM. The numerical analysis was realized in a vertical area with an assumption of homogeneous subsoil (a heterogeneous environment partly influences results) stressing the observation of uplifts. The stress on the overburden caused by uplift is often a concomitant circumstance of a flood and may indicate threats to the safety of a flood dike.

This paper was supported by Grant No. 1/0704/09

\section{REFERENCES}

[1] SEFTRANS. A Simple and Efficient Two - Dimensional Groundwater Flow and Transport Model. Oxford Geotechnica International. Oxford, Durham, Prague, Dublin, 1996

[2] MUCHA, I., ŠESTAKOV, V.: Hydraulics of underground water. ALFA, Bratislava, 1987

[3] THOMAS,S.D.,YUAN,F.: Groundwater and the Environment.
The 2nd Annual Environmental Engineering Workshop. Groundwater Modelling Case Studies. Oxford Geotechnica International. University of Durham, 1996

[4] GRAMBLIČKOVÁ, D., BEDNÁROVÁ, E.: Lessons learned reviewing the safety of a flood dike using the finite element method. In: Water Management 6/2006, Prague, pp. 179-180 